\title{
Outcomes of Nordic mental health systems: life expectancy of patients with mental disorders ${ }^{\dagger}$
}

\author{
Kristian Wahlbeck, Jeanette Westman, Merete Nordentoft, Mika Gissler and Thomas Munk Laursen
}

\section{Background}

People with mental disorders evince excess mortality due to natural and unnatural deaths. The relative life expectancy of people with mental disorders is a proxy measure of effectiveness of social policy and health service provision.

\section{Aims}

To evaluate trends in health outcomes of people with serious mental disorders.

\section{Method}

We examined nationwide 5-year consecutive cohorts of people admitted to hospital for mental disorders in Denmark Finland and Sweden in 1987-2006. In each country the risk population was identified from hospital discharge registers and mortality data were retrieved from cause-of-death registers. The main outcome measure was life expectancy at age 15 years.

\section{Results}

People admitted to hospital for a mental disorder had a twoto threefold higher mortality than the general population in all three countries studied. This gap in life expectancy was more pronounced for men than for women. The gap decreased between 1987 and 2006 in these countries, especially for women. The notable exception was Swedish men with mental disorders. In spite of the positive general trend, men with mental disorders still live 20 years less, and women 15 years less, than the general population.

\section{Conclusions}

During the era of deinstitutionalisation the life expectancy gap for people with mental disorders has somewhat diminished in the three Nordic countries. Our results support further development of the Nordic welfare state model, i.e. tax-funded community-based public services and social protection. Health promotion actions, improved access to healthcare and prevention of suicides and violence are needed to further reduce the life expectancy gap.

\section{Declaration of interest}

None.
In most high-income countries mental health services have been transformed from hospital-centred to integrated communitybased services. Social inclusion and empowerment of people with mental disorders have gradually replaced institutional care and paternalistic attitudes. However, evidence to support or challenge the change in mental health policy is scant and system-level outcome studies are rare. ${ }^{1}$ People with mental disorders evince an excess mortality, due to both death from disease and medical conditions and death from injury. ${ }^{2}$ The excess mortality among people with mental disorders can only partially be explained by an increased risk of suicide. In Finland a longitudinal cohort study with a followup period of 17 years indicated a 50\% mortality increase for those with a diagnosed mental disorder, mainly due to respiratory and cardiovascular disorders. ${ }^{3}$ Among people with schizophrenia, Finnish and Swedish population cohort studies have reported a mortality rate for diseases and medical conditions more than double that of the general population, even when adjusted for lifestyle risk factors. $^{4-7}$ A nationwide Danish register study reported excessive mortality among people admitted to hospital for schizophrenia, bipolar disorder and major depressive disorder. ${ }^{8}$ The findings of the Nordic studies are not unique. Unanimously, studies across Europe have replicated the finding of excessive mortality, both in psychiatric hospital in-patients, ${ }^{9-12}$ discharged patients, ${ }^{13,14}$ and in patients with mental disorders in primary care. ${ }^{15}$

Life expectancy is determined by factors affecting health such as lifestyle, environment, health literacy and access to healthcare. A gap in life expectancy between psychiatric patients and the population at large is a proxy indicator of the effectiveness of policy, services and health promotion actions, including suicide prevention, directed at this disadvantaged population. A

†See editorial, pp. 441-442, this issue. successful national mental health strategy and service provision should be reflected as a narrowing of the mortality gap. We set out to evaluate the effectiveness of the mental health policies of three Nordic countries (total population about 20 million persons) by analysing nationwide life expectancy trends among people with at least one hospital admission due to a mental disorder.

The Nordic countries are highly developed welfare states with a long tradition of egalitarian health and welfare policies. Improvements in mental health and mental health services have been on the agenda in these countries during recent decades. Mental health services have undergone a thorough reform, from an emphasis on psychiatric institutional care to the current emphasis on out-patient care and social participation. The reduction in numbers of hospital beds for psychiatric patients (Fig. 1), especially for those with long-term disorders, has been met by an increase of psychiatric treatment in primary care and by growth in housing institutions provided by social care. ${ }^{16}$ Overall, the reform of mental healthcare has changed living conditions for people with mental disorders profoundly and one can therefore expect an effect on life expectancy. Despite these reforms, few studies have addressed trends in mortality among people with mental disorder, and their findings have been inconsistent. ${ }^{17,18}$ To evaluate the achievements of the Nordic mental healthcare reforms, we studied the life expectancy of people with mental disorders in Denmark, Finland and Sweden.

\section{Method}

\section{Case definition}

Cases included were identified from discharge diagnoses recorded in the nationwide hospital registers. The Nordic countries use the 


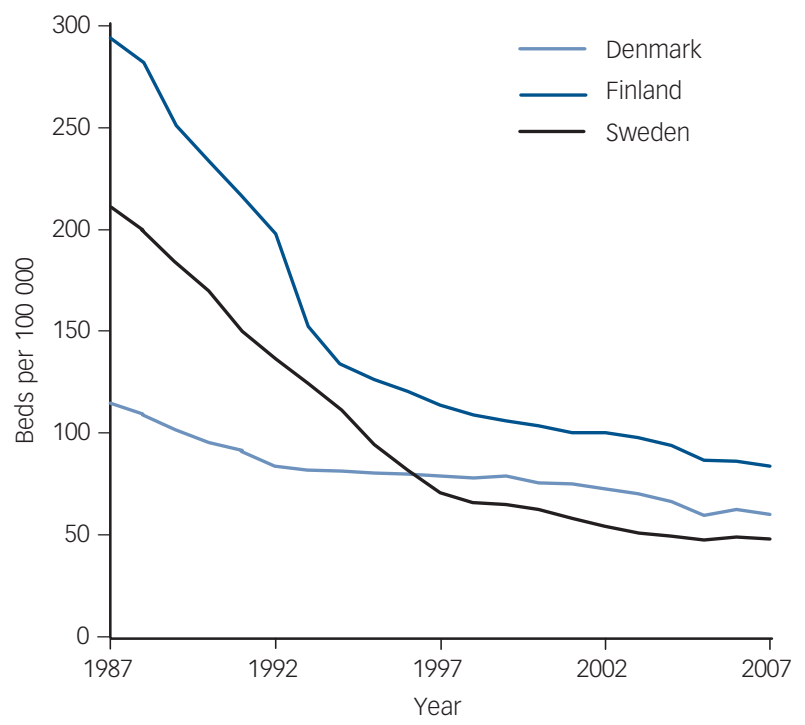

Fig. 1 Psychiatric hospital beds per 100000 inhabitants in Denmark, Finland and Sweden 1987-2007.

International Classification of Diseases (ICD) for definition and classification of psychiatric and physical diseases in their hospital discharge registers. During the period 1987-2006 three ICD versions were used in Nordic hospital discharge and cause-ofdeath registers. We used the main diagnoses recorded for each hospital admission, and categorised them according to ICD-10 diagnostic groups. ${ }^{19}$ The diagnoses in ICD-8 and ICD-9 were transformed to ICD-10 diagnoses.

All cases of patients with a primary diagnosis of any mental disorder (ICD-10 codes F00-F69) were retrieved from the hospital registers. Patients with a diagnosis of intellectual disability (F70-79) at any point were excluded. Hospital admissions due to organic mental disorders such as dementia (F00-09) resulted in exclusion of the patient's data, starting from the first admission due to dementia and any episode afterwards. Cases of intellectual disability and dementia were excluded because of the high risk of premature mortality inherent to the organic nature of these conditions.

\section{Causes of death}

In each country studied, information on cause of death is recorded in a national register. The main cause of death is based on the information available in the death certificate. The causes of death are checked by medically trained personnel in each of the study countries. For this study we analysed separately deaths from diseases and medical conditions (ICD-10 codes A00-R99), suicide (X60-84) and external causes other than suicide (V01-Y98, excluding X60-84).

\section{Nordic registers}

\section{Denmark}

The Danish psychiatric central register covers all psychiatric in-patient facilities in Denmark and has been computerised since 1969. ${ }^{20}$ The diagnostic system used until 1993 was ICD-8, replaced in 1994 by the ICD-10 classification. The Danish cause-of-death register contains computerised information about all deaths of Danish citizens and residents, date of death, place of death and cause of death. It has a high level of completeness and its validity has been evaluated with excellent results. ${ }^{21}$

\section{Finland}

The Finnish hospital discharge register includes data on all in-patient episodes on an individual level since 1969. For diagnosis, ICD-8 was used during the period 1969-86, ICD-9 during the period 1987-95 and ICD-10 from 1996 onwards. The register has been found to be a valid and reliable tool for epidemiological research. ${ }^{22}$ The Finnish cause-of-death register records data on the deaths of all citizens and permanent residents in Finland; it has a high level of completeness. All diagnoses of the causes of death have to pass a routine validation carried out by Statistics Finland and unclear cases are judged by a panel. ${ }^{23}$

\section{Sweden}

The Swedish hospital discharge register covers all hospitals in Sweden. It contains data on all hospital admissions and discharge diagnoses according to ICD since 1987. For diagnosis, ICD-9 was used during the period 1987-96 and ICD-10 from 1997 onwards. The register has a high level of completeness. ${ }^{24}$ The Swedish causeof-death register contains information about deaths of all Swedish residents classified according to ICD-9 and ICD-10. The coding error estimated from a sample of deaths was approximately $3 \%{ }^{25}$

\section{Statistical analysis}

The observation period started on 1 January 1987 and ended 31 December 2006, and was further divided in four 5-year periods: 1987-91, 1992-6, 1997-2001 and 2002-6. The risk population was formed for each 5-year period separately, including all patients with at least one hospital admission due to a mental disorder during the 5-year period. Mortality rates were calculated for age groups 15-29 years, 30-44 years, $45-59$ years, 60-74 years and 75 years or more. We used the Nordic standard population in 2000 for standardising mortality rates. ${ }^{26}$ The standardised mortality rates among mental health patients were compared with general population mortality rates, ${ }^{27}$ calculating observed/ expected ratios. For people at risk, i.e. patients admitted to hospital for a mental disorder, we calculated life expectancy at age 15 years and for ages 15-64 years, separately for men and women, using Wiesler's method with 1-year age stratification. ${ }^{28}$ Life expectancies were aggregated for each 5 -year study period to diminish random variation. We used published World Health Organization life expectancy data (http://data.euro.who.int/hfadb) for general population comparisons.

\section{Results}

People with a mental disorder severe enough to justify hospital admission had a two- to threefold mortality compared with that of the general population in each country. Our results indicated that life expectancy of people with mental disorders had increased in all three countries. The life expectancy gap of people with serious mental disorders decreased between 1987 and 2006, with the exception of male patients in Sweden (Fig. 2). This gap is wider for men than for women, regardless of country and time period (Tables 1 and 2).

The trends in relative mortality in each age group reflected the trends in the whole population. In Denmark there was a notable reduction of mortality risk among young people with mental disorders. In Finland a favourable trend was seen among women of all age groups, but the mortality trend for men was clearly less favourable. In Sweden the picture was more diverse: the relative mortality risk improved among women younger than 45 years, but a slight worsening was seen among older women. Among 


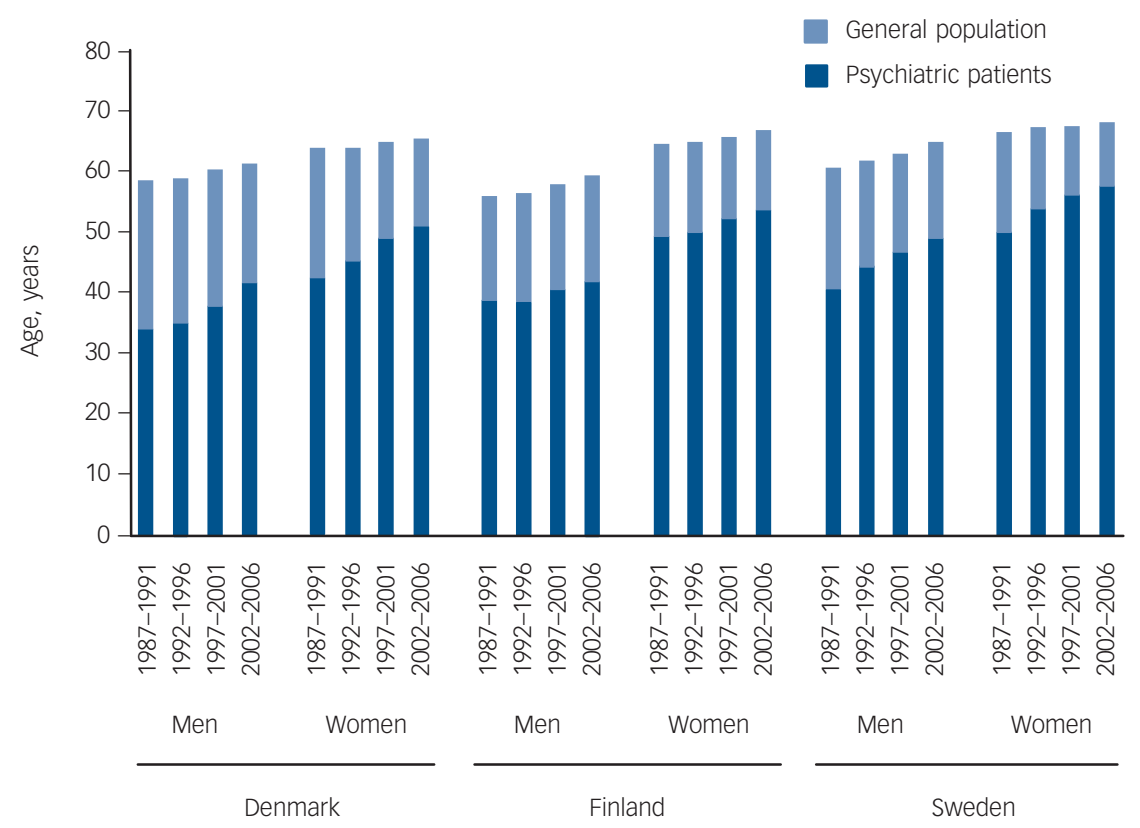

Fig. 2 Total life expectancy among psychiatric patients and general population in Denmark, Finland and Sweden 1987-2006 at 15 years of age.

Swedish men with mental disorders the relative risk of death increased over time, except for those over 75 years old.

At the beginning of the study period the life expectancy of people with mental disorders was lower in Denmark and Finland than in Sweden. During the study period the life expectancy of people with mental disorders increased by about 7 years in Denmark and Finland, but increased by only half of that in Sweden. In spite of this, in 2002-6 the life expectancy gap of people with mental disorders was still greater in Denmark than in the other two countries. In Sweden the increase in life expectancy among men equalled the increase in the general population, but there was no sign of a reduction in the men's life expectancy gap. The relative risk of suicide and other external causes increased among men with mental disorders. In spite of the positive developments, Nordic men with mental disorders still live 20 years less, and Nordic women 15 years less, than the general population, due to excess mortality in all categories of causes of death.

\section{Discussion}

In the Nordic countries the transition from psychiatric hospital care to community-based mental health services has been supported by a high level of social security and reasonable access to public primary care services. In addition to public healthcare, a comprehensive range of social services, including supported housing and social activities, is provided by the local authorities (the municipalities). The annual number of in-patients has remained largely unchanged over time despite the decrease in the number of hospital beds. This is explained by the decrease in average length of stay in psychiatric hospitals. There has been a decrease in the number of long-stay patients in psychiatric hospital care. The decrease in the number of beds has been accompanied by the development of community care. Community mental health services were implemented gradually from the mid-1980s and were fully implemented at the end of the 1990s, although community care development was slowed in Finland and Sweden by the economic recession in the beginning of the 1990s. In Finland, for instance, the number of out-patient mental health visits approximately doubled during the study period. ${ }^{29}$

\section{Mortality determinants}

Several explanations for the excess mortality among people with mental disorders have been suggested. These include an unhealthy lifestyle ${ }^{30}$ inadequate access to good-quality physical healthcare, ${ }^{31,32}$ and a culture of not taking physical disease into consideration when treating psychiatric patients. ${ }^{33}$ The excess mortality also reflects multiple vulnerabilities. People with mental disorders are more often poor, unemployed, single and marginalised, all known risk factors for poor health and premature mortality. ${ }^{34}$

Our data show a temporal association between deinstitutionalisation and increases in life expectancy among people admitted to hospital for a mental disorder. Stigma underlies many of the barriers to healthcare access. ${ }^{35}$ Deinstitutionalisation and destigmatisation of mental disorders are mutually interlinked, and a specific effect of destigmatisation, with effects on helpseeking behaviour and healthcare supply to people with mental disorders, cannot be ruled out as the cause of increased life expectancy. In 2006 a Europe-wide opinion poll reported that attitudes towards people with mental disorders were more positive among residents of northern and western Europe, including the Scandinavian countries. ${ }^{36}$ We believe that the development of community care may have contributed to more favourable attitudes towards people with mental disorders.

Life expectancy is related to social capital and income equity. In the European Union the Nordic countries have the highest levels of formal as well as informal social capital. ${ }^{37}$ Contrary to the decline in social capital reported from some other Western countries during the study period, no such decline has been reported from the Nordic countries. ${ }^{38}$ Social inequalities in health have remained largely unchanged in the Nordic countries in spite 


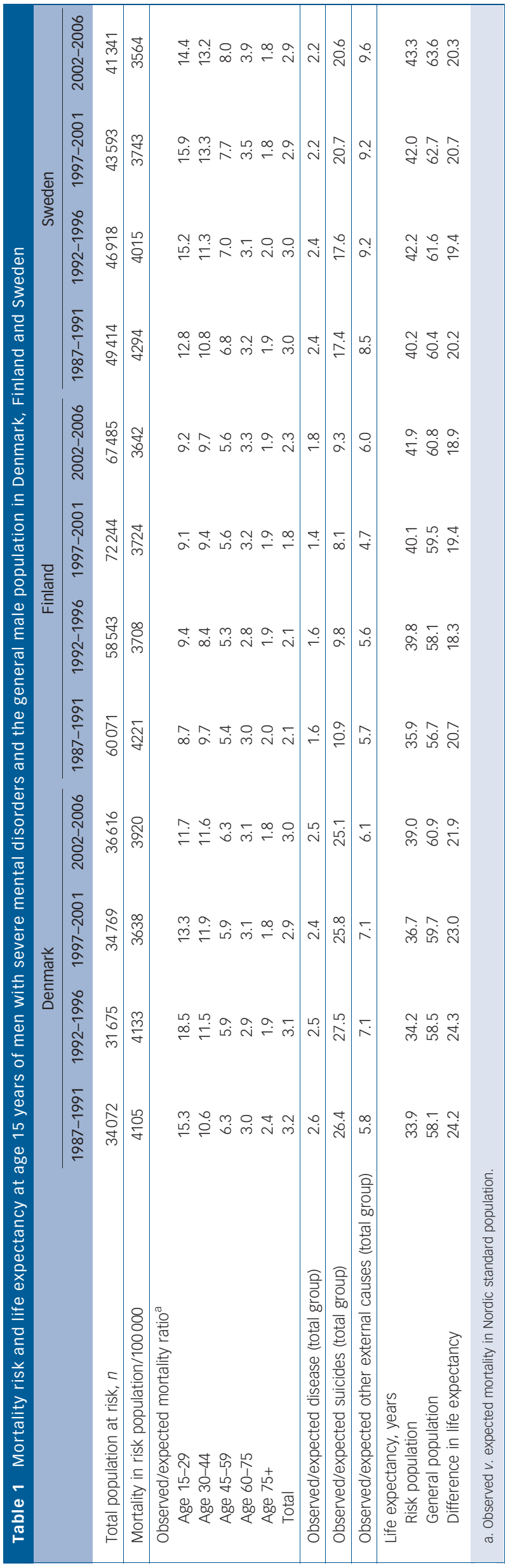

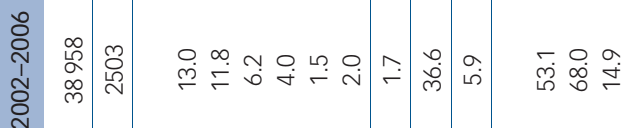

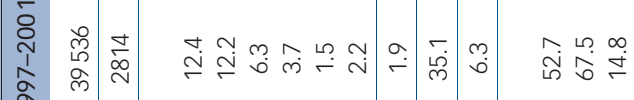

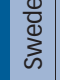

ฉำ

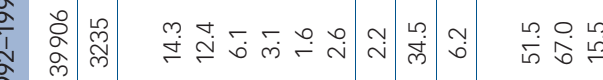

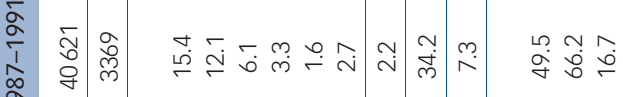

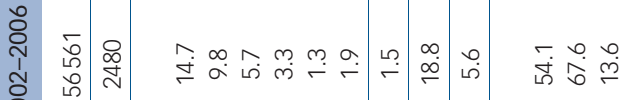

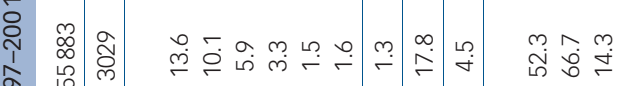
a

त.

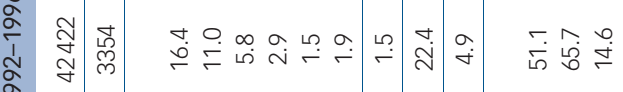

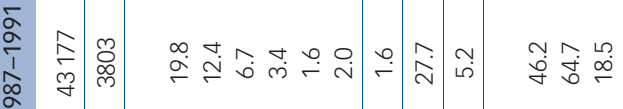

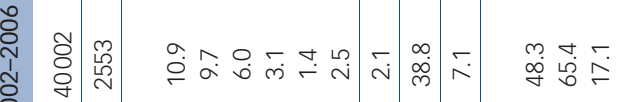

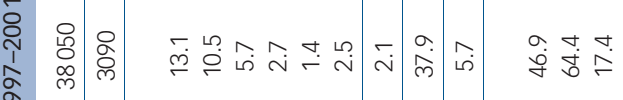

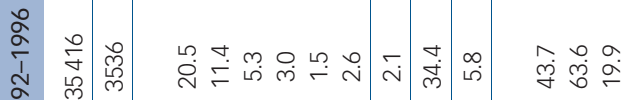

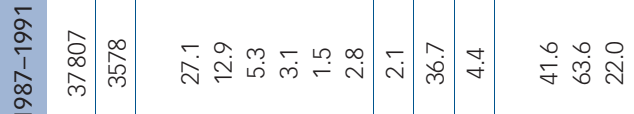
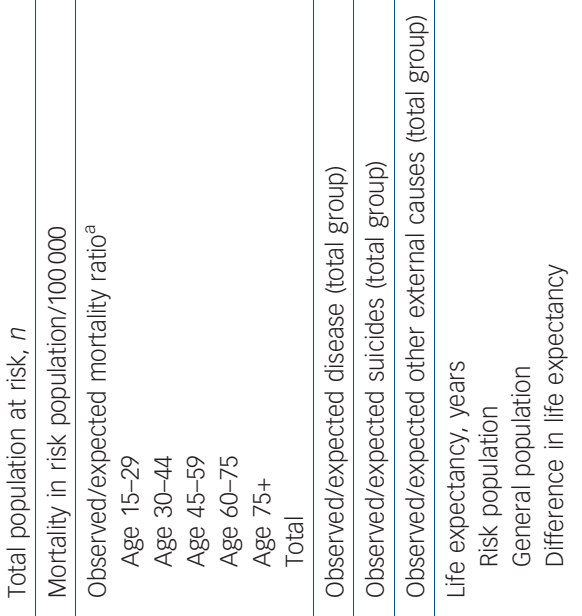
of the economic recession at the beginning of the $1990 \mathrm{~s} .{ }^{39}$ Our results thus do not seem to reflect major changes in the social determinants of health.

Data from Russia indicate a strong link between trends in premature mortality and alcohol consumption, especially in men. ${ }^{40}$ However, over the study period the consumption of strong spirits decreased slightly in Sweden only (from 1.31 to 1.21 pure alcohol per person aged 15 years and over) and the consumption of strong spirits increased in Denmark and Finland. ${ }^{41}$ It therefore does not seem plausible that the positive developments in life expectancy depend on population-level changes in the use of alcohol.

\section{Suicide prevention policies}

Our rather disturbing data from Sweden indicate that during a period of 20 years no progress in reducing the life expectancy gap for men with mental disorders has occurred. We show that the relative risk for death by suicide or other external causes has increased among Swedish men with a mental disorder when compared with Swedish men in general. Suicide mortality decreased considerably in all three countries during the observation period. ${ }^{26}$ Males are more likely to die by suicide, and our data indicate that suicide among men with mental disorders decreased somewhat more than suicides in the general population in Denmark and Finland, but not in Sweden. A small-area analysis from Finland indicated that improved community care contributed to the reduced risk of suicide among people with mental disorders. ${ }^{42}$ Transition to community care may have been less successful in Sweden than in the two other countries; observations indicate that in Sweden local municipalities in many instances failed to provide community services to discharged long-term patients, and a major national psychiatry development programme was initiated in 2006 to mitigate the problems. ${ }^{43}$ National suicide prevention action plans were developed in all three countries (Finland in 1991, Sweden in 1995 and Denmark in 1998), but the implementation actions were more strongly backed up by governments in Denmark and Finland than in Sweden. ${ }^{44}$ The lack of a strongly implemented Swedish suicide prevention policy may in part explain why suicide prevention among the male population with mental disorders failed in Sweden but has been successful in Denmark and Finland.

\section{Gender effects}

Our data also indicate gender-specific effects. The increase in life expectancy in people with mental disorders was lower among men than among women in all three countries. The gender effect may reflect differences in seeking help from community health services; European studies have indicated that women talk to a health professional about mental health issues twice as often as men. ${ }^{45}$ It may also reflect the gender-specific nature of mental disorders: in general, women tend to have more affective disorders and men to have more substance use disorders. ${ }^{46}$ If the shift to communitybased service is less beneficial for people with substance use disorders, this would result in a disadvantage for men with mental disorders.

\section{Study limitations}

This study benefited from stable healthcare systems and cause-ofdeath registers with full population coverage, but comparability between countries may be compromised by differences in healthcare systems such as variations in referral practices. Caution should be exerted when comparing absolute numbers, but trends constitute a more robust comparative measure. Our data sources were limited to three of the Nordic countries. We were unable to include data from Norway because data on hospital discharges in the Norwegian patient register did not include the personal identification codes needed for register linkage until 2009. ${ }^{47}$

Our case identification was based on hospital discharge registers, and thus people with mental disorders who had not been admitted to hospital or diagnosed in the period from 1987 to 2006 were not included in our data. Less serious non-hospitalised cases of mental disorders, possibly with a better life expectancy outcome, are not included. Changes in health systems and diagnostic practices may cause heterogeneity over time in the composition of the risk population in our study, but the stable number of in-patients over the study period indicates that the composition of the in-patient populations had not undergone a major shift. Autopsy rates have declined in the Nordic countries during the study period, but the rate of deaths lacking a cause of death in the registers remains small, ranging from $0.2 \%$ in Finland to $0.8 \%$ in Sweden and $1.1 \%$ in Denmark.

We caution against bold generalisation of our findings to other countries, as the beneficial effects seen in relation to deinstitutionalisation of psychiatry in the three Nordic countries may be highly contextual and dependent on socioeconomic protective factors which are stronger in these than in many other countries. Such possible protective factors include strong welfare policies, good social protection, high level of social capital and beneficial population attitudes towards people with mental disorders.

\section{Implications of the study}

Life expectancy is a coarse measure of how society succeeds in meeting the needs of people with mental disorders. Our data indicate progress in Denmark and Finland, and among women in Sweden. At the same time our study highlights that progress has been modest, and that the mortality gap among men in Sweden remains owing to a failure to prevent suicide and deaths due to violence or accidents in this group. Reforms that lead to closure of psychiatric institutions have an inherent risk of abandoning patients to their own devices. Our results show that deinstitutionalisation can be implemented while maintaining or even improving the life expectancy of people with mental disorders across countries. In spite of the transition of mental health services, however, the life expectancy gap has remained largely unchanged over 20 years, and major health inequalities persist between people with mental disorders and the rest of the population.

\section{Kristian Wahlbeck, DMedSc, Nordic School of Public Health, Nordic Research Academy in Mental Health, Gothenburg, Sweden, and National Institute for Health and Welfare (THL), Vaasa, Finland; Jeanette Westman, PhD, Nordic School of Public Health, Nordic Research Academy in Mental Health, Gothenburg, Sweden; Merete Nordentoft, MD, Nordic School of Public Health, Nordic Research Academy in Mental Health, Gothenburg, Sweden, and Psychiatric Center Bispebjerg, Bispebjerg Hospital, Copenhagen, Denmark; Mika Gissler, PhD, Nordic School of Public Health Nordic Research Academy in Mental Health, Gothenburg, Sweden, and THL, Helsinki, Finland; Thomas Munk Laursen, PhD, Nordic School of Public Health, Nordic Research Academy in Mental Health, Gothenburg, Sweden, and National Centre for Register-Based Research, Aarhus University, Aarhus, Denmark \\ Correspondence: Dr Kristian Wahlbeck, National Institute for Health and Welfare (THL), Department of Mental Health and Substance Abuse Services, POBox 30, FIN-00271 Helsinki, Finland. Email: kristian.wahlbeck@thl.fi \\ First received 22 Jul 2010, final revision 15 Nov 2010, accepted 17 Jan 2011}

\section{Funding}

This research was supported by a grant from the Nordic Council of Ministers and by grant 2008-0885 from the Swedish Council for Social Research. 


\section{References}

1 Thornicroft G, Tansella M. Components of a modern mental health service: a pragmatic balance of community and hospital care. Overview of systematic evidence. Br J Psychiatry 2004; 185: 283-90.

2 Harris EC, Barraclough B. Excess mortality of mental disorder. Br J Psychiatry 1998; 173: 11-53.

3 Joukamaa $M$, Heliövaara $M$, Knekt $P$, Aromaa A, Raitasalo R, Lehtinen V. Mental disorders and cause-specific mortality. Br J Psychiatry 2001; 179 498-502.

4 Joukamaa M, Heliövaara M, Knekt P, Aromaa A, Raitasalo R, Lehtinen V. Schizophrenia, neuroleptic medication and mortality. Br J Psychiatry 2006; 188: $122-7$

5 Ösby U, Correia N, Brandt L, Ekbom A, Sparen P. Mortality and causes of death in schizophrenia in Stockholm county, Sweden. Schizophr Res 2000; 45: 21-8.

6 Fors BM, Isacson D, Bingefors K, Widerlöv B. Mortality among persons with schizophrenia in Sweden: an epidemiological study. Nord J Psychiatry 2007; 61: 252-9.

7 Tidemalm D, Waern M, Stefansson CG, Elofsson S, Runeson B. Excess mortality in persons with severe mental disorder in Sweden: a cohort study of 12103 individuals with and without contact with psychiatric services. Clin Pract Epidemiol Ment Health 2008; 4: 23.

8 Laursen TM, Munk-Olsen T, Nordentoft M, Mortensen PB. Increased mortality among patients admitted with major psychiatric disorders: a register-based study comparing mortality in unipolar depressive disorder, bipolar affective disorder, schizoaffective disorder, and schizophrenia. J Clin Psychiatry 2007 68: 899-907.

9 Hewer W, Rössler W, Fatkenheuer B, Löffler W. Mortality among patients in psychiatric hospitals in Germany. Acta Psychiatr Scand 1995; 91: 174-9.

10 Hewer W, Rössler W. Mortality of patients with functional psychiatric illnesses during in-patient treatment [in German]. Fortschr Neurol Psychiatr 1997; 65: 171-81.

11 Perakis A, Kolaitis G, Kordoutis P, Kranidioti M, Tsiantis J. Mortality among institutionalised people with learning disabilities in Greece: a 30-year survey at the Leros PIKPA asylum. Br J Psychiatry 1995; 167 (suppl 28): 70-7.

12 Räsänen S, Hakko H, Viilo K, Meyer-Rochow VB, Moring J. Excess mortality among long-stay psychiatric patients in Northern Finland. Soc Psychiatry Psychiatr Epidemiol 2003; 38: 297-304.

13 Salazar-Fraile J, Gomez-Beneyto M, Perez-Hoyos S, Hurtado-Navarro I. Mortality among psychiatric patients referred to the mental health services in Valencia. Soc Psychiatry Psychiatr Epidemiol 1998; 33: 224-9.

14 Stark C, MacLeod M, Hall D, O'Brien F, Pelosi A. Mortality after discharge from long-term psychiatric care in Scotland, 1977-94: a retrospective cohort study. BMC Public Health 2003; 3: 30 .

15 Ensinck KT, Schuurman AG, van den Akker AM, Metsemakers JF, Kester AD Knottnerus JA, et al. Is there an increased risk of dying after depression? Am J Epidemiol 2002; 156: 1043-8.

16 Gissler M, Tuori T, Wahlbeck K, The Nordic Reference Group. Mental health in the Nordic countries. Health Statistics in the Nordic Countries 2005 Helsestatistik for de Nordiske Lande 2005. Nordic Medico-Statistical Committee, 2007.

17 Ösby U, Correia N, Brandt L, Ekbom A, Sparen P. Time trends in schizophrenia mortality in Stockholm county, Sweden: cohort study. BMJ 2000; 321: 483-4.

18 Heilä H, Haukka J, Suvisaari J, Lönnqvist J. Mortality among patients with schizophrenia and reduced psychiatric hospital care. Psychol Med 2005; 35 725-32

19 World Health Organization. International Statistical Classification of Diseases and Related Health Problems (ICD-10). WHO, 1992.

20 Munk-Jorgensen $\mathrm{P}$, Mortensen PB. The Danish Psychiatric Central Register. Dan Med Bull 1997; 44: 82-4.

21 Juel K, Helweg-Larsen K. The Danish registers of causes of death. Dan Med Bull 1999; 46: 354-7

22 Keskimäki I, Aro S. The accuracy of data on diagnoses, procedures and accidents in the Finnish Hospital Discharge Register. Int J Health Serv 1991; 2: 15-21.

23 Lahti RA, Penttila A. The validity of death certificates: routine validation of death certification and its effects on mortality statistics. Forensic Sci Int 2001; 115: 15-32.

24 Swedish Ministry of Health and Social Affairs. Kvalitet och innehåll $i$ patientregistret. Utskrivningar från slutenvården 1964-2007 och besök i specialiserad öppenvård (exklusive primärvårdsbesök) 1997-2007 [Quality and content of the Swedish Patient Register]. Socialstyrelsen, 2009.
25 Johansson LA, Westerling R. Comparing Swedish hospital discharge records with death certificates: implications for mortality statistics. Int J Epidemiol 2000; 29: 495-502.

26 Nordic Medico-Statistical Committee. Health Statistics in the Nordic Countries 2007. Helsestatistik for de Nordiske Lande 2007. NOMESCO, 2009.

27 World Health Organization Regional Office for Europe. European Health For All Database (HFA-DB). WHO Regional Office for Europe, 2010 (http://data.euro.who.int/hfadb/).

28 Wiesler $\mathrm{H}$. Une méthode simple pour la construction de tables de mortalité abrégées. Proceedings of the First World Population Conference, Rome, vol. 4. United Nations, 1954.

29 Karlsson N, Wahlbeck K. Från Reformintention Till Praxis: Mentalvårdens Utveckling i Finland Efter År 1990 [From Reform Intentions to Practice: Developments in Finnish Mental Health Care Since 1990]. Rapport 24/2010. Finland National Institute for Health and Welfare, 2010 (http://www.thl.fi/ thl-client/pdfs/d0d504f0-d878-4a19-97b3-e3b060f9b09a)

30 Osborn DP, Levy G, Nazareth I, Petersen I, Islam A, King MB. Relative risk of cardiovascular and cancer mortality in people with severe mental illness from the United Kingdom's general practice research database. Arch Gen Psychiatry 2007; 64: 242-9.

31 Druss BG, Bradford WD, Rosenheck RA, Radford MJ, Krumholz HM. Quality of medical care and excess mortality in older patients with mental disorders. Arch Gen Psychiatry 2001; 58: 565-72.

32 Laursen TM, Munk-Olsen T, Agerbo E, Gasse C, Mortensen PB. Somatic hospital contacts, invasive cardiac procedures, and mortality from heart disease in patients with severe mental disorder. Arch Gen Psychiatry 2009; 66: 713-20.

33 Sims ACP. Mortality statistics in psychiatry. Br J Psychiatry 2001; 179: 477-8.

34 Fryers $T$, Melzer $D$, Jenkins $R$, Brugha $T$. The distribution of the common mental disorders: social inequalities in Europe. Clin Pract Epidemiol Ment Health 2005; 1: 14.

35 Link BG, Phelan JC. Stigma and its public health implications. Lancet 2006; 367: 528-9.

36 European Commission. Mental Well-being. Special Eurobarometer 248/wave 64.4. EC Directorate General Communication, 2006 (http://ec.europa.eu/ health/ph_information/documents/ebs_248_en.pdf).

37 Pichler F, Wallace C. Patterns of formal and informal social capital in Europe. Eur Sociol Rev 2007; 23: 423-35.

38 Halpern D. Social Capital. Polity Press, 2005

39 Lahelma $\mathrm{E}$, Kivelä $\mathrm{K}$, Roos $\mathrm{E}$, Tuominen $\mathrm{T}$, Dahl E, Diderichsen $\mathrm{F}$, et al. Analysing changes of health inequalities in the Nordic welfare states. Soc Sci Med 2002; 55: 609-25.

40 Zaridze D, Brennan P, Boreham J, Boroda A, Karpov R, Lazarev A, et al. Alcohol and cause-specific mortality in Russia: a retrospective case-control study of 48,557 adult deaths. Lancet 2009; 373: 2201-14.

41 Finland National Institute for Health and Welfare. Nordic Alcohol Statistics 2008. Finland National Institute for Health and Welfare, 2009 (http:// www.stakes.fi/tilastot/tilastotiedotteet/2009/Tr20_09.pdf).

42 Pirkola S, Sund R, Sailas E, Wahlbeck K. Community mental-health services and suicide rate in Finland: a nationwide small-area analysis. Lancet 2009; 373: 147-53.

43 Swedish Ministry of Health and Social Affairs. Ambition och ansvar. Nationell strategi för utveckling av samhällets insatser till personer med psykiska sjukdomar och funktionshinder. Slutbetänkande av Nationell psykiatrisamordning. SOU 2006:100 [Ambition and Responsibility. National Strategy for People with Mental Disorders and Disabilities]. Socialdepartementet, 2006 (http://www.sweden.gov.se/content/1/c6/07/31/ 78/f8d9f649.pdf)

44 Nordentoft M, Gudnason K, Laigaard A, Koch I, Bille-Brahe U, Hjorth Madsen $\mathrm{B}$, et al. Forslag til Handlingsplan til Forebyggelse af Selvmordsforsøg og Selvmord i Danmark [Action Plan for Prevention of Suicide and Suicide Attempts in Denmark]. Denmark National Board of Health, 1998.

45 Alonso J, Angermeyer MC, Bernert S, Bruffaerts R, Brugha TS, Bryson $\mathrm{H}$, et al. Use of mental health services in Europe: results from the European Study of the Epidemiology of Mental Disorders (ESEMeD) project. Acta Psychiatr Scand Suppl 2004; 420: 47-54

46 Kessler RC, McGonagle KA, Zhao S, Nelson CB, Hughes M, Eshleman S, et al. Lifetime and 12-month prevalence of DSM-III-R psychiatric disorders in the United States. Results from the National Comorbidity Survey. Arch Gen Psychiatry 1994; 51: 8-19.

47 Norwegian Patient Register. Aktivitetsdata i Psykisk Helsevern for Voksne 2008. Rapport IS-1749 [Activity Data from Adult Mental Health Services 2008] Helsedirektoratet, 2010. 